\title{
Chemical Composition Characteristics and Usability Evaluation of Flue-cured Tobacco Leaves -A Case Study of Tobacco-producing Areas in Chongqing Municipality, China
}

\author{
Bangwei Huang,Chaofu Wei, Hua Deng \\ College of Resource and Environment \\ Southwest University \\ Chongqing, China \\ e-mail: weicf@swu.edu.cn
}

\author{
JiakeLv \\ Collegeof Computer and Information Science \\ Southwest University \\ Chongqing, China \\ e-mail:lvjiake@gq.com
}

Abstract-The market of Chongqing flue-cured tobacco always lacks a relatively perfect evaluation of its quality objective system. In order to solve the mentioned problem, this paper will carry on the appraisal to the chemical of fluecured tobacco and availability. There are nine main tobaccoproducing districts in Chongqing municipality, China. We divided them into three type regionsdue to the geographic features; 234 flue-cured tobacco samplesof Yunyan87 (including B2F, C3F, X2F) had been collected in 2014 to test the content of total sugar, reducing sugar, nicotine, total nitrogen, potassium and chlorine. Besides, its feature was evaluated at the same time. Theresults showed that:(1)The contents of total sugar and reducing sugar and the ratio of nitrogen/alkali of Yunyan 87 in the samples were relatively higher, while the potassium and chorine were relatively lower, the ratio of potassium/chorine was higher with larger variation, however, the other chemical compositions and ratios were all within proper ranges.(2)The contents and ratios of chemical compositions differed significantly between the samples from different classes and geological landforms.(3)The class indexes of chemical compositions from high grade to low gradewere:C3F、B2F、X2F, and the usability indexes of chemical compositions in different geology and landformwere: the northeast area of Chongqing, the southeast area of Chongqing, the central area of Chongqing. Therefore, the characteristics of chemical compositions and usability of flue-cured tobacco differed from different geological and landforms in Chongqing tobacco planting areas.

Keywords-flue-cured tobacco; yunyan87;chemical composition; geology andlandform; usability

\section{I.INTRODUCTION}

Nowadays, the individualities of tobacco materials are strongly a market demand, especially for the stability, the homogeneity and compositeness of the raw material. In the course of acquisitions, the main good evidences of the leaf tobacco are the appearances and physical properties. Therefore, in this study we need to analyze on internal quality of tobacco leaves in different districts to ensure the characteristics orientation of quality style and to guarantee the similarity of external and internal quality, which has a vital significance to satisfy with the development of cigarette brand and to promote by the supply of tobacco and improve the characteristics of tobacco leaf quality $[1,2]$.

The evaluation of tobacco quality is, traditionally, identified by testing the sample [3]. But the data is not clear. Furthermore, in some extent, it is easily influenced by assessors. While the quality of tobacco leaves is decided for the content of chemical compositions, which are seriously influenced by the appearance quality of fluecured tobacco leaves and so on [4]. The usability of fluecured tobacco is directly decided by the process of making tobaccos, and the value of flue-cured tobacco is also depending on the classification of sample quality evaluation $[5,6]$. The existed researches $[7,8]$ have studied the climate of tobacco area and the soil factors, but there are hardly researches about the classification of geological features in Chongqing tobacco areas and analyses on the chemical composition of tobacco in Chongqing. Therefore, in this paper the quality of chemical composition of Yunyan87 in Chongqing tobacco 
areaswill be studied. In order to get quantified and comply with the industrial availability indexes, these will become comprehensive evaluation of chemical compositions of tobacco leafin different geological features.

\section{MaterialsandMetheods}

\section{A. Studies regions}

Chongqing is located in the upper reaches of the Yangtze River, the southeast of Sichuan. The tobacco planting areas are mainly distributed in the eastern area where have less pollution in the Wuling Mountain and in the Three Gorges Reservoir Area. Its position is longitude $106^{\circ} 23^{\prime}-110^{\circ} 11^{\prime}$ degree east, and locate in latitude $28^{\circ} 09^{\prime}$ $31^{\circ} 44^{\prime}$ degrees north. In 2014 , pilot studies were selected in the nine major tobacco planting districts of Chongqing. According to the geological features in the 9 districts, there would be divided into 3 areas. The northeast area of Chongqing, including Wushan and Wuxi, have more terrains, and in the Karst landforms there are stone forest, Karst valley, funnels and the stoneholes in the geography. The southeast area of Chongqing, including Pengshui, Qianjiang and Youyang, are mainly distributed along the river to thel,Il terraces which are preserved well. Also, thelterrace has a small slope at the ground and is higher than the surface of the river. But the II terrace is not preserved well because of the erosion. The central area of Chongqing, including Nanchuan, Wulong, Fengdu and Shizhu, are the hilly terrain with narrow valley. The geographical position is shown in Figure 1.

\section{B. Samples}

The variety of trial in Chongqing tobacco planting areas mainly are Yunyan87. Selected in the tobacco fields where contain fecundsoil. In order to guarantee

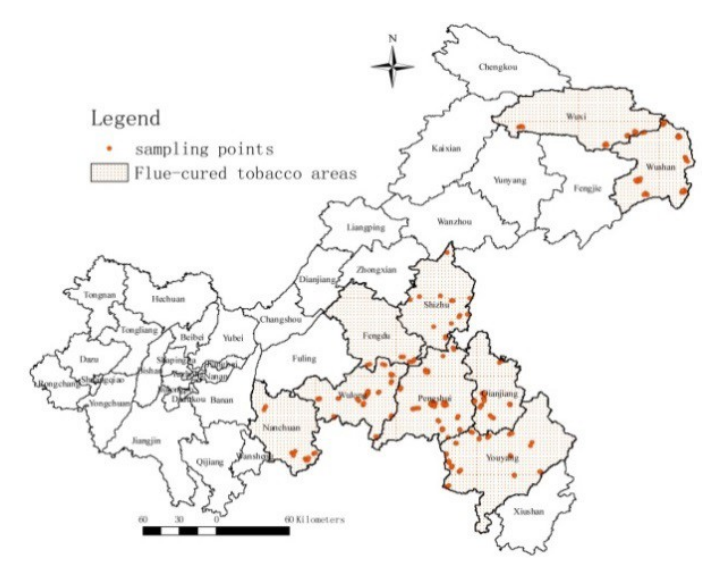

Figure 1. Chongqing flue-cured tobacco planting areas

representation of the samples, grading would be used by the sampling method. A total of 234 flue-cured tobacco samples were collected, divided into 3 categories. In the Southeast area of Chongqing includes 44 flue-cured tobacco samples which have 14 samples of B2F, 16 samples of $\mathrm{C} 3 \mathrm{~F}$ and 14 samples of X2F. In the northeast area of Chongqing includes 118 flue-cured tobacco samples which have 37 samples of B2F, 44 samples of $\mathrm{C} 3 \mathrm{~F}$ and 37 samples of $\mathrm{X} 2 \mathrm{~F}$. In the central area of Chongqing includes 72 flue-cured tobacco samples which have 27 samples of B2F, 19 samples of $\mathrm{C} 3 \mathrm{~F}$ and 26 samples of X2F. The mentioned above measures have passed $85 \%$ in qualification rate. Each portion weighed $3.0 \mathrm{~kg}$ to analyze on main chemical compositions.

\section{Experimental Methods}

\section{1) Index Test}

After the samples were exposedto mini cyclone, it would be scanned by infrared spectroscopy in the Near Infrared of the MPA (Bruker, Germany). It is using Near Infrared Prediction Model to calculate the quantitative data regarding the content of total sugar, reducing sugar, nicotine, total nitrogen, potassium and chlorine [9].Then, it also can be calculated in the ratio of nitrogen/nicotine, the ratio of total sugar/nicotine and the ratio of potassium/chorine of Yunyan87 in the samples. The Descriptive Statistics, Membership Function [10] and Principal Components [11,12 ] are used to analyze on participating indicators and to calculate the Chemical compositionsUsabilityIndex(CCUI) of flue-cured tobacco in order to confirm a comprehensive evaluation on chemical compositions of flue-cured tobacco. 


\section{2) Statistics methods}

SPSS17.0 [13] and EXCEL would be used to test results, and Multiple Comparisons are analyzed for Duncan'sNew Multiple Range method.

\section{III.Results AND Discussion}

\section{A. Descriptive statistics analysis of chemical compositions}

It's widely acknowledged that suitable content range of chemical compositions offlue-cured tobaccois about $18 \%$ and $22 \%$ for total sugar, $16 \%$ and $20 \%$ for reducing sugar, $1.5 \%$ and $3.5 \%$ for nicotine and total nitrogen, $0.3 \%$ and $0.8 \%$ for chlorine, more than $2 \%$ for potassium, 8 and 12 regarding the ratio of total sugar/nicotine, approximately 1 for the ratio of nitrogen/alkali, more than 4 for the ratio of potassium/chorine [2,14]. According to Table I, chemical composition variation coefficients of the general trend are chlorine, potassium, nicotine, total sugar, reducing sugar, total nitrogen. On the table of the narrative, Yunyan 87 of tobacco are all in the range of requirement, including total nitrogen, nicotine, the ratio of total sugar/nicotine, the potassium/chorine. While,the total sugar, reducing sugar and the ratio of nitrogen/alkali is slightly higher than the requirement of the flue-cured tobacco. And the chlorine ion and potassium ion is slightly lower than the average value. Among them, the variation of chlorine ion, the ratio of total sugar to nicotine and the potassium ion are considered. What's more, it also shows that different tobacco planting areas of Chongqing at the ratio of potassium/chlorine vary greatly, which the coefficient of variation of the ratio of potassium/chlorine has a strong variation greater than 1 . From the coefficient of skewness, some of them are negative skewed peaks which the coefficient are less than 0 including total sugar, reducing sugar and the ratio of nitrogen/nicotine. Others are the positive skewed peaks. From the coefficient of kurtosis, concentration with chlorine, the ratio of total sugar/nicotine and the ratio of potassium/chlorine have longer tail than normal distributions.

TABLE I.

Descriptive Statistics of Chemical Compositions onChongQingTobaccoYunyan 87in Tobacco Leaves

\begin{tabular}{|c|c|c|c|c|c|c|c|}
\hline Indexes & Average & Maximum & Minimum & $\begin{array}{l}\text { Standard } \\
\text { Deviation }\end{array}$ & $\begin{array}{l}\text { Coefficient } \\
\text { of Variation }\end{array}$ & $\begin{array}{l}\text { Coefficient } \\
\text { of Skewness }\end{array}$ & $\begin{array}{l}\text { Coefficient } \\
\text { of Kurtosis }\end{array}$ \\
\hline Total Sugar $\% \%$ & 23.93 & 36.20 & 10.20 & 4.90 & 20.47 & -0.36 & -0.16 \\
\hline Reducing Sugar $\%$ & 21.80 & 31.60 & 9.88 & 4.41 & 20.23 & -0.42 & -0.02 \\
\hline Nicotine $/ \%$ & 3.06 & 5.88 & 0.72 & 0.91 & 29.74 & 0.06 & -0.20 \\
\hline Chlorine/\% & 0.12 & 0.75 & 0.00 & 0.10 & 83.33 & 2.65 & 9.63 \\
\hline Potassium/\% & 1.90 & 3.61 & 0.70 & 0.57 & 30.00 & 0.28 & -0.21 \\
\hline Nitrogen/\% & 2.13 & 3.42 & 1.25 & 0.36 & 16.90 & 0.48 & 0.27 \\
\hline Total Sugar/Nicotine & 9.02 & 39.17 & 2.24 & 5.00 & 55.43 & 2.77 & 12.56 \\
\hline Nitrogen/Nicotine & 1.43 & 2.23 & 0.39 & 0.33 & 23.08 & -0.30 & 0.37 \\
\hline Potassium/Chlorine & 33.12 & 294.00 & 1.73 & 42.50 & 128.32 & 3.12 & 11.42 \\
\hline
\end{tabular}

\section{B. The difference between the levels of main chemical compositions}

According to Table II, the differencesamong each grade are significant. The content of nicotine,the ratio of nitrogen/nicotineand chlorine from high to low is $\mathrm{B} 2 \mathrm{~F}$, $\mathrm{C} 3 \mathrm{~F}, \mathrm{X} 2 \mathrm{~F}$, which is significant different among grades. The grade of $\mathrm{C} 3 \mathrm{~F}$ and $\mathrm{X} 2 \mathrm{~F}$ in total nitrogen content is not significantly different, but these are significantly higher than B2F. Also, the content of total sugar from high to low is $\mathrm{C} 3 \mathrm{~F}, \mathrm{~B} 2 \mathrm{~F}, \mathrm{X} 2 \mathrm{~F}$, which is significant different among grades. And the content of reducing sugar from high to low is $\mathrm{C} 3 \mathrm{~F}, \mathrm{~B} 2 \mathrm{~F}, \mathrm{X} 2 \mathrm{~F}$, which is significantly different among grades. Then, the grade of $\mathrm{C} 3 \mathrm{~F}$ and $\mathrm{X} 2 \mathrm{~F}$ in total sugar/nicotine is not significant different, but these all are significantly higher than B2F. What's more, the content of potassium from high to low is $\mathrm{X} 2 \mathrm{~F}, \mathrm{C} 3 \mathrm{~F}$, $\mathrm{B} 2 \mathrm{~F}$, which is significantly different among grades. The grade of $\mathrm{C} 3 \mathrm{~F}$ and $\mathrm{B} 2 \mathrm{~F}$ in the ratio of potassium/chlorine 
is not significantly different, but these all are significantly lower than X2F.

table II. Difference Analysis of Main Chemical Compositions of Flue-Cured Tobacco in Different Grades

\begin{tabular}{|c|c|c|c|c|c|c|c|c|c|c|}
\hline Grade & $\begin{array}{c}\text { Sample } \\
\text { Size }\end{array}$ & $\begin{array}{c}\text { Total } \\
\text { Sugar/\% }\end{array}$ & $\begin{array}{c}\text { Reducin } \\
\text { g Sugar/ } \\
\%\end{array}$ & $\begin{array}{c}\text { Nicotine } \\
/ \%\end{array}$ & $\begin{array}{c}\text { Chlorine } \\
/ \%\end{array}$ & $\begin{array}{c}\text { Potassium } \\
/ \%\end{array}$ & $\begin{array}{c}\text { Nitrogen } \\
/ \%\end{array}$ & $\begin{array}{l}\text { Total Sugar } \\
\text { /Nicotine }\end{array}$ & $\begin{array}{l}\text { Nitrogen } \\
\text { / Nicotine }\end{array}$ & $\begin{array}{l}\text { Potassium } \\
\text { /chlorine }\end{array}$ \\
\hline B2F & 234 & $21.13 \mathrm{Cc}$ & $19.51 \mathrm{Bb}$ & $3.89 \mathrm{Aa}$ & $0.15 \mathrm{Aa}$ & $1.66 \mathrm{Cc}$ & $2.37 \mathrm{Aa}$ & $5.70 \mathrm{Bb}$ & $1.65 \mathrm{Aa}$ & $21.99 \mathrm{Bb}$ \\
\hline $\mathrm{C} 3 \mathrm{~F}$ & 234 & $26.25 \mathrm{Aa}$ & $23.71 \mathrm{Aa}$ & $2.98 \mathrm{Bb}$ & $0.10 \mathrm{Bb}$ & $1.85 \mathrm{Bb}$ & $2.06 \mathrm{Bb}$ & $10.12 \mathrm{Aa}$ & $1.45 \mathrm{Bb}$ & $29.10 \mathrm{Bb}$ \\
\hline $\mathrm{X} 2 \mathrm{~F}$ & 234 & $24.31 \mathrm{Bb}$ & $22.08 \mathrm{Cc}$ & $2.32 \mathrm{Cc}$ & $2.32 \mathrm{Cc}$ & $2.21 \mathrm{Aa}$ & $1.96 \mathrm{Bb}$ & $11.2 \mathrm{Aa}$ & $1.19 \mathrm{Cc}$ & $49.50 \mathrm{Aa}$ \\
\hline
\end{tabular}

table III. Correlation Analysis on Different Geological Types and the Chemical IndeXes of Tobacco Grades

\begin{tabular}{|c|c|c|c|c|c|c|c|c|c|c|c|}
\hline $\begin{array}{l}\text { Geolo } \\
\text { gical } \\
\text { Types }\end{array}$ & $\begin{array}{l}\text { Grade } \\
\text { s }\end{array}$ & $\begin{array}{l}\text { Sam } \\
\text { ple } \\
\text { Size }\end{array}$ & $\begin{array}{l}\text { Total } \\
\text { Sugar/\% }\end{array}$ & $\begin{array}{l}\text { Reducing } \\
\text { Sugar } \%\end{array}$ & $\begin{array}{l}\text { Nicotin } \\
\text { e } \\
/ \%\end{array}$ & $\begin{array}{c}\text { Chlorine } \\
/ \%\end{array}$ & $\begin{array}{l}\text { Potassiu } \\
\text { m } \\
\text { /\% }\end{array}$ & $\begin{array}{c}\text { Nitrogen } \\
/ \%\end{array}$ & $\begin{array}{l}\text { Total Sugar } \\
\text { /Nicotine }\end{array}$ & $\begin{array}{l}\text { Nitroge } \\
\text { n } \\
\text { / } \\
\text { Nicotine }\end{array}$ & $\begin{array}{l}\text { Potassium } \\
\text { /chlorine }\end{array}$ \\
\hline I & B2F & 14 & $22.51 \mathrm{Aa}$ & 19.96Aa & $3.72 \mathrm{Aa}$ & $0.16 \mathrm{Aa}$ & $1.17 \mathrm{Bb}$ & $2.18 \mathrm{Bb}$ & 6.43Aa & $1.72 \mathrm{Aa}$ & $15.34 \mathrm{Aa}$ \\
\hline II & $\mathrm{B} 2 \mathrm{~F}$ & 37 & $20.36 \mathrm{Aa}$ & $18.90 \mathrm{Aa}$ & $4.03 \mathrm{Aa}$ & $0.17 \mathrm{Aa}$ & $1.85 \mathrm{Aa}$ & $2.46 \mathrm{Aa}$ & $5.24 \mathrm{Aa}$ & $1.65 \mathrm{Aa}$ & $23.64 \mathrm{Aa}$ \\
\hline III & $\mathrm{B} 2 \mathrm{~F}$ & 27 & $21.46 \mathrm{Aa}$ & $20.13 \mathrm{Aa}$ & 3.79Aa & $0.13 \mathrm{Aa}$ & $1.67 \mathrm{Bb}$ & $2.35 \mathrm{Aab}$ & $5.96 \mathrm{Aa}$ & $1.62 \mathrm{Aa}$ & $23.18 \mathrm{Aa}$ \\
\hline I & $\mathrm{C} 3 \mathrm{~F}$ & 16 & 26.36Aa & $23.86 \mathrm{Aa}$ & $2.36 \mathrm{Bb}$ & $0.10 \mathrm{Aa}$ & $1.72 \mathrm{Bab}$ & $1.95 \mathrm{Aa}$ & $14.90 \mathrm{Aa}$ & $1.21 \mathrm{Bb}$ & $21.51 \mathrm{Aa}$ \\
\hline II & $\mathrm{C} 3 \mathrm{~F}$ & 44 & $26.18 \mathrm{Aa}$ & $23.60 \mathrm{Aa}$ & $3.17 \mathrm{Aa}$ & $0.10 \mathrm{Aa}$ & $1.97 \mathrm{Aa}$ & $2.12 \mathrm{Aa}$ & $8.88 \mathrm{Bb}$ & $1.50 \mathrm{Aa}$ & 33.39Aa \\
\hline III & $\mathrm{C} 3 \mathrm{~F}$ & 19 & $26.32 \mathrm{Aa}$ & $23.81 \mathrm{Aa}$ & $3.06 \mathrm{Aa}$ & $0.13 \mathrm{Aa}$ & $1.67 \mathrm{Bb}$ & $2.02 \mathrm{Aa}$ & $8.97 \mathrm{Bb}$ & $1.54 \mathrm{Aa}$ & $26.01 \mathrm{Aa}$ \\
\hline I & $\mathrm{X} 2 \mathrm{~F}$ & 14 & $22.08 \mathrm{Bb}$ & $20.36 \mathrm{Bb}$ & $1.98 \mathrm{Aa}$ & $0.15 \mathrm{Aa}$ & $1.81 \mathrm{Bb}$ & $1.98 \mathrm{Aa}$ & $12.20 \mathrm{Aa}$ & $1.03 \mathrm{Aa}$ & $19.88 \mathrm{Aa}$ \\
\hline II & $\mathrm{X} 2 \mathrm{~F}$ & 37 & 24.06Bab & $21.51 \mathrm{Bb}$ & $2.42 \mathrm{Aa}$ & $0.06 \mathrm{Bb}$ & $2.36 \mathrm{Aa}$ & $2.00 \mathrm{Aa}$ & $10.44 \mathrm{Aa}$ & $1.21 \mathrm{Aa}$ & 68.16Aa \\
\hline III & $\mathrm{X} 2 \mathrm{~F}$ & 26 & $25.85 \mathrm{Aa}$ & $23.81 \mathrm{Aa}$ & 2.36Aa & $0.10 \mathrm{AaBb}$ & $2.22 \mathrm{Aa}$ & $1.90 \mathrm{Aa}$ & $11.75 \mathrm{Aa}$ & $1.25 \mathrm{Aa}$ & $40.70 \mathrm{AaBb}$ \\
\hline
\end{tabular}

I stands for the northeast area of Chongqing, II stands for the southeast area of Chongqing and III stands for the central area of Chongqing.

C. Differences of the main chemical composition in different regions

According to the geological types in the places of mainly planting tobacco areas in Chongqing of nine counties, these are divided into 3 regions. As is shown in Table III, the grade of $\mathrm{B} 2 \mathrm{~F}$ in potassium is not significant differences in the northeast area of Chongqing and the central area of Chongqing, but these all are significantly lower than the southeast area of Chongqing. The content of potassium from high to low is the southeast area of Chongqing, the central area of Chongqing, the northeast area of Chongqing, which is extremely significant difference among regions. The rest of chemical index were not significant.

In the grade of $\mathrm{C} 3 \mathrm{~F}$, nicotine and nitrogen/nicotine are not significant differences in the southeast area of Chongqing and the central area of Chongqing, but these all are significantly higher than the northeast area of Chongqing. The content of potassium from high to low is the southeast area of Chongqing, The northeast area of Chongqing, the central area of Chongqing, which is significant difference among regions. The ratio of total sugar/nicotine is not significant differences in the southeast area of Chongqing and the central area of Chongqing, but these all are significantly higher than the northeast area of Chongqing. The rest of chemical index were not significant.

In addition, in the grade of $\mathrm{X} 2 \mathrm{~F}$, the content of total sugar from high to low is the central area of Chongqing, the southeast area of Chongqing, the northeast area of Chongqing, which is significantly different in these regions. The reducing sugars are not significant difference in the southeast area of Chongqing and the northeast area of Chongqing, but the level of reducing sugar of both regions is significantly lower than the central area of 
Table IV. The Index Selection, the Infection Point and The Weight Value of the Usability Evaluation of Chemical Compositions In Flue-Cured Tobacco

\begin{tabular}{|c|c|c|c|c|c|c|}
\hline Indexes & $\begin{array}{c}\text { Function } \\
\text { Types }\end{array}$ & $\begin{array}{l}\text { Lower } \\
\text { Limit/ } x_{1}\end{array}$ & $\begin{array}{c}\text { Lower Limit of } \\
\text { Optimal Value/ } x_{3}\end{array}$ & $\begin{array}{c}\text { Upper Limit of } \\
\text { Optimal Value/ } x_{4}\end{array}$ & $\begin{array}{c}\text { Upper } \\
\text { Limit/ } x_{2}\end{array}$ & $\begin{array}{c}\text { Weight } \\
\text { Values/\% }\end{array}$ \\
\hline Nitrogen & & 1.1 & 2.0 & 2.3 & 3.4 & 9.05 \\
\hline Nicotine & & 1.2 & 2.1 & 2.4 & 3.5 & 13.25 \\
\hline Total Sugar & & 10.0 & 20.0 & 28.0 & 35.0 & 10.75 \\
\hline Reducing Sugar & & 11.5 & 19.0 & 20.0 & 27.0 & 10.85 \\
\hline Total & $\mathrm{p}$ function & 2.0 & 8.5 & 9.5 & 15.0 & 12.37 \\
\hline Sugar/Nicotine & & 0.55 & 0.95 & 1.05 & 1.45 & 9.52 \\
\hline Nitrogen/Nicotine & & 0.2 & 0.3 & 0.8 & 1.2 & 10.52 \\
\hline Chloride & & 0.8 & & & 2.5 & 13.75 \\
\hline $\begin{array}{c}\text { Potassium } \\
\text { Potassium/Chlorine }\end{array}$ & $\begin{array}{l}\text { membershi } \\
\text { p function }\end{array}$ & 0.8 & & & 8.0 & 9.94 \\
\hline
\end{tabular}

Chongqing. The content of chlorine from high to low is the northeast area of Chongqing, the central area of Chongqing, the southeast area of Chongqing, which is significantly different among regions. What's more, the content of potassium are not significantly different between the southeast area of Chongqing and the central area of Chongqing, but they are significantly lower than the northeast area of Chongqing. The ratio of potassium/chlorine is not significant difference in the southeast area of Chongqing and the northeast area of Chongqing, but they are significantly higher than the central area of Chongqing. The rest of chemical index were not significant.

D.The comprehensive evaluation of chemical composition in Chongqing tobacco planting areas of Yunyan87

Due to the range of every index is not consistent, it is valuable to use the main chemical compositions indexes which are mentioned to flue-cured tobacco chemical compositions, regarding Chongqing tobacco planting areas of Yunyan87. In order to eliminate the influence of the dimension, it will use the theory of fuzzy mathematics to calculate the quality index figure, which could make the raw data of the evaluation index convert between 0.1 and 1. Hence, there are two types of membership function: S-types membership function and parabolic membership function. The formulas are:
S-types membership function:

$$
f(x)=\left\{\begin{array}{lr}
1.0 & x \geq x 2 \\
0.9(x-x 1) /(x 2-x 1) & x 1<x<x 2 \\
0.1 & x \leq x 1
\end{array}\right.
$$

Parabolic membership function:

$$
f(x)=\left\{\begin{array}{lr}
0.1 & x<x 1 ; x>x 2 \\
0.9(x-x 1) /(x 3-x 1) & x 1 \leq x<x 3 \\
1.0 & x 3 \leq x \leq x 4 \\
1.0-0.9(x-x 4) /(x 2-x 4) & x 4<x \leq x 2
\end{array}\right.
$$

Thus, the membership values of each component indexes were calculated, which reflect the pros and cons on the chemical availability [15]. Its maximum is 1.0 , which represents best condition of the chemical availability in flue-cured tobacco. The membership values reduce from 1 to 0.1 meaning the chemical compositions of state are getting worse. According to the practical production, the minimum value of membership is 0.1 .

In the formula, the alphabet of $x_{1}, x_{2}, x_{3}$ and $x_{4}$ each separately represent lower limit, upper limit, lower limit of optimal value, upper limit of optimal value, and $x$ represent for the actual content of the chemical composition. Based on the practical experience and the past researches [16, 17], it will locate the evaluation indexes and break point. At the same time, the 234 samples should be analyzed by the principal components analysis. Three principal components are supposed to extract total contribution which is more than $80 \%$. Also, 
the chemical compositions indexes will be calculated to get weight value [18] (Table IV).

\section{.E. The comparison of chemical compositions index}

The chemical composition indexes can be calculated by the formula of $C C U I=\sum_{i=1}^{n} W i \cdot B i$. In this formula, the Wiand $B i$ represent for the weights coefficient and membership value on the $i$ chemical index, respectively. The values of CCUI range from 0 to 100 . The higher the value, the better the usability of flue-cured chemical composition is.

\section{1) The usability indexes of flue-cured chemical compositions in different grades}

According to Table $\mathrm{V}$, the grade of $\mathrm{C} 3 \mathrm{~F}$ has the highest usability index figure which is on average of 71.65. The grade of B2F is the second usability and the grade of $\mathrm{X} 2 \mathrm{~F}$ is the third usability. The standard deviation of these three of grades is less than $6 \%$. It proves the difference among the values is small. And the variation coefficient of grades is less than $10 \%$, it becomes relatively close to all values.

Table V. The Comparison of Usability Indexes of Flue-Cured Chemical Composition in Different Grades

\begin{tabular}{|c|c|c|c|c|}
\hline Grades & Average & Variations & $\begin{array}{l}\text { Standard } \\
\text { Deviation }\end{array}$ & $\begin{array}{c}\text { Variation Coefficients } \\
\%\end{array}$ \\
\hline B2F & 68.42 & $63.43 \sim 74.27$ & 5.45 & 7.96 \\
\hline $\mathrm{C} 3 \mathrm{~F}$ & 71.65 & $65.77 \sim 77.42$ & 5.34 & 7.45 \\
\hline $\mathrm{X} 2 \mathrm{~F}$ & 67.05 & $61.06 \sim 72.38$ & 5.96 & 8.90 \\
\hline
\end{tabular}

Wh the northeast area of Chongqing

the southeast area of Chongqing

- the central area of Chongqing.

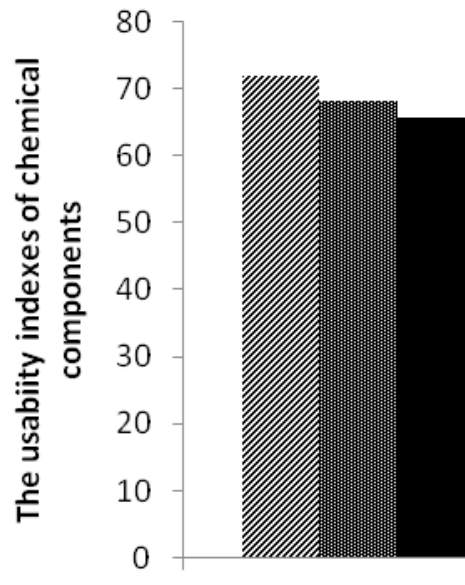

B2F

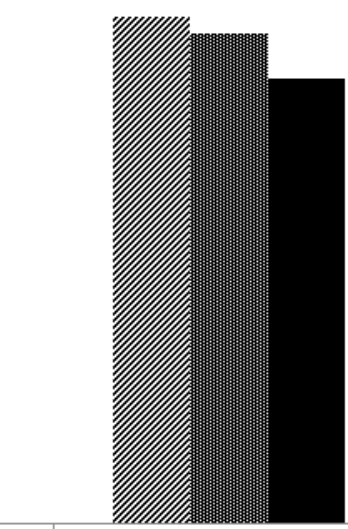

$\mathrm{C} 3 \mathrm{~F}$

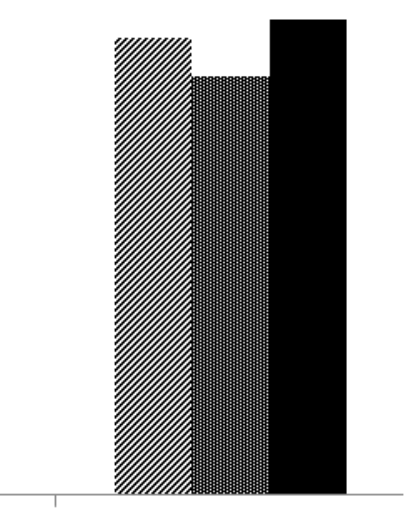

$\mathrm{X} 2 \mathrm{~F}$

Figure 2. The usability indexes of flue-cured chemical composition in different geological areas

2) The usability indexes of flue-cured chemical composition in different geological areas

According to the Figure 2, regarding the grade of B2F and $\mathrm{C} 3 \mathrm{~F}$, the usability index in the northeast area of Chongqing is highest, which is 71.68 and 75.42, respectively. The lowest grade in the central area of 
Chongqing is 65.49 and 66.30 , respectively. In the grade of $\mathrm{X} 2 \mathrm{~F}$, the highest and the lowest grade are 70.68 in the central area of Chongqing and is 62.32 in the southeast area of Chongqing, respectively. In summary, the northeast area of Chongqing highest usability of chemical composition and the central area of Chongqing provide lowest usability of chemical composition.

\section{IV.CONCLUSIONS}

The Yunyan87 tobacco leaves have good chemical composition usability. It has high total sugar, reducing sugar, the nitrogen, nicotine, the ratio of potassium/chlorine and moderate total sugar/nicotine. Also, low potassium and chlorine levels have been associated with the tobacco leaves. Potash fertilizer is one of the important fertilizers in the production of tobacco. Therefore, the efficiency of fertilizing in the planting

Also geography difference influences the chemical composition of Yunyan87.

Membership values are used to measure the quality status of chemical availability. This method has certain guidance for comprehensive evaluation analysis on the usability of chemical compositions in flue-cured tobacco, which can be calculated by the comparison of chemical composition directly to get availability indexes. According to the analysis on the usability indexes of chemical compositions in different grades of flue-cured tobacco, it is easy to find the usability indexes. In different regions, the analysis on the usability indexes of chemical compositions indicates significant differences. The results of the usability indexes of chemical composition in each grade get the highest figure of 71.65 with $\mathrm{C} 3 \mathrm{~F}$ and the lowest figure of 67.05 with $\mathrm{X} 2 \mathrm{~F}$. According to the analysis of the usability indexes of chemical composition in different Chongqing regions, it shows that the northeast area of Chongqing has the highest usability indexes and the central area of Chongqing has the lowest index.

At a matter of fact, the qualities of flue-cured tobacco include appearance, chemical, physical, smoking, safe factors and etc., but this study only evaluate on the content of chemical composition and its ratio to the usability of flue-cured quality. Therefore, in the future we process can improve the quality and production [19]. Moreover, fertilization can improve the fragrance of Yunyan87. As mentioned above, to improve the content of potassium, it can be fulfilled by increasing the usage of potash fertilizer and by increasing the utilization rate of potash fertilizer. In addition, if the content of chlorinein flue-cured tobaccois too high or too low, it willreduce the yield and quality of Yunyan87 [20]. So, chlorine fertilizer should be applied appropriately in Chongqing tobacco area. But overall, in the future Chongqing regions should improve genetic part of flue-cured tobacco, promote the environmental-friendly tobacco corps and increase the maturity of tobacco leaves on the field. Furthermore, carbon and nitrogen metabolism could be increased, and carbohydrate of tobacco leaves should be regulated to the appropriate level [21]. Beyond these, the chemical composition is different among grades.

can study on these combine with chemical composition. The impact onthe quality of tobaccois not only the chemical composition of tobacco leaves, but the effect of chemical composition on the quality of tobacco leaveswhich is quitecomplex. Different cigarettes companies have different requirements to the tobacco leaves. Because of the special landscape of Chongqing tobacco areas, how to cope with the requirements of individuation in different regions are the key, which are connected with the local styles and the raw material. There should be further research to establish the comprehensive evaluation indexes of flue-cured tobacco in Chongqing.

\section{ACKNOWLEDGMENT}

The authors are grateful to the Head of the School of Studies in Chemistry, Southwest University, for providing the laboratory facilities. And this research was supported by the Application of the Study on the Condition of Soil and AgriculturalGeology (NY20140601070001) and Fertilizer less Nitrogen Efficiency of Flue-cured Tobacco (NY2014050107007) from China Tobacco Company in Chongqing.

\section{REFERENCES}


[1] Y.J. Tang, "Orientation of style and characteristics of tobacco leaves. Chinese Tobacco Science,” 2008, vol. 29(3), pp. 1-5.

[2] K.Y. Yan, and M.Q. Zhao, Tobacco Science. Beijing: Science Press,2008, pp. 95-107.

[3] C.H. Callicutt, R.H. Cox, F. Hsu, et al. Regulatory Toxichology and Pharmacology, 2006, vol.46, pp. 2-16.

[4] T.X. Yang, J. Wen, W.L. Chen, Z.E. Liang, et al. "Analysis of ecological factors and flue-cured tobacco quality of Liangshan tobacco growing area," Tobacco Science, 2009, vol.5, pp. 52-56.

[5] J.X. Li, C.Y. Jiang, Y.J. Tang, and G.L. Liang, "Analysis on compatibility of peculiar tobacco leaves from different producing areas,"Guizhou Agricultural Science, 2008, vol.36(5), pp. 53-55.

[6] W. Chen, S.G. Wang, Y.J. Tang, J. Lu, et al. "Analysis of the dominant climatic factors influencing the chemical compositions of flue-cured tobacco in different tobacco-planting areas," Journal of Plant Nutrition and Fertilizer, 2008, vol.14(1), pp. 144-150.

[7] G.W. Du, C. Yang, N.J. Guo, and H.B. Liu,"Effects of climate factors on chemical compositions of flue-cured tobacco in Chongqing," Chinese Agriculture Science Bulletin, 2014, vol.29(1), pp. 98-102.

[8] J.X. Bao, M. Gao, and J.C. Qin,"Analysis of the spatial variability of tobacco-planting soil basic environment in Chongqing," South China Journal of Agricultural, 2006, vol.19(3), pp. 409-413.

[9] W. Du, X.L. Tan, and J.H. Yi,"Evaluation of leaf tobacco quality using chemical composition data,"ActatabacariaSinica, 2007, $\operatorname{vol.13(3),~pp.25-31.~}$

[10]Y.S. Ding, Y. He, J.L. Cao, and G.M. Zhao,"Chemical component characteristics and usability of flue-cured tobacco leaves in Dali prefecture," Chinese Tobacco Science, 2009, vol.3, pp. 13-18.

[11]J.M. Ma, G.S. Liu, X.D. Shi, Y.W. Wei, et al.,"Applicationof principal component analysis and cluster analysis in tobacco quality evaluation," Chinese Tobacco Science, 2009, vol.7, pp. 57-60
[12]X.B. Zhang, C. Xia, B.K. Xiang, et al. "Suitability evaluation of chemical components in Yunnan tobacco with Grey Incidence Analysis," Chinese Tobacco Science, 2014, vol.10, pp. 32-35.

[13]C.X. Li, Y. Shao, and L.N. Jiang, Biostatistics. Science Press, 2008, pp. $85-121$.

[14]G.S. Liu G S, Tobacco Cultivation. China Agriculture Press, 2003, pp. $68-82$

[15]Y.Y. Li, J.Y. Huang, Z.C. Xu, et al. "Analysis of chemical components of flue-cured tobacco in Luoyang tobacco growing area characteristics," Anhui Agricultural Sciences, 2004, vol.34(9), pp. 1903-1904

[16]Z.C. Xu, Y.Y. Li, H.Q. Xiao, and L. Wang,"Evaluation of ecological factors and flue-cured tobacco quality in tobacco-planting areas in Southern Hunan, China,” Journal of plantecology, 2008, vol.329(1), pp. 226-234.

[17]N.L.Benowitz, (Ed). Nicotine safety and toxicity. Oxford University Press, 1998, pp. 3-16.

[18]X.H. Deng, J.H. Zhou, H.Q. Yang, S.Y. Zhao, et al.,"Construction and empirical analysis of evaluating quantitative system of the appearance quality of flue-cured tobacco in Hunan,"Scientia Agricultura Sinica, 2007, vol.40(9), pp. 2036-2044.

[19]X.B. Xiao, Y.Q. Ma, S.F. Zhang, and Y.Y. Zhang,"Effects of different potassium application methods on the quality of tobacco Yunyan87," 2014, vol.4(26), pp. 374-376.

[20]A.C. Xu, F. Li, C. Wang,"Advance in effect of chloride on fluecured tobacco growth and development and leaf quality," Chinese Tobacco Science, 2007, vol.28(2), pp. 6-9.

[21]T. Perfetti , B. Gordon , W. Coleman Iii , W. Morgan, "Determination of the transfer efficiency of d-nicotine to mainstream smoke,"Betitr.Takaforsch. Int.2001, vol.19, pp. 237 244. 